\title{
Report
}

\section{Position Dependence for Count Rates in a Polyethylene Naphthalate Survey Meter}

\author{
Philip NGuyen, ${ }^{* 1}$ Hidehito Nakamura, ${ }^{* 1,2}$ Yoshiyuki ShiRakawa, ${ }^{* 2}$ Tatsuya Yamada ${ }^{* 1}$ and \\ SentarO TAKAHASHI ${ }^{* 1}$
}

(Received on September 24, 2014)

(Accepted on December 25, 2014)

\begin{abstract}
A thin polyethylene naphthalate $(\mathrm{PEN})$ sheet $(72 \times 140 \times 0.5 \mathrm{~mm})$ with one face enhanced with prism treatment was used for a survey meter. PEN has a relatively high effective refractive index of 1.70 , which directly affects light propagation generated in the sheet. We show its radiation counting response at a $9 \times 23$ array of different locations on the detection window of the PEN survey meter, when irradiated with beta particles from a ${ }^{90} \mathrm{Sr}$ radioactive source. The variability in radiation counts on the detection window, obtained by dividing the maximum value by the minimum value, was 1.23 along the Y-axis and 1.05 along the $\mathrm{X}$-axis. This knowledge can be useful in the design of radiation detectors mounting PEN sheets.
\end{abstract}

KEY WORDS: polyethylene naphthalate, survey meter, position dependence, strontium-90.

\section{INTRODUCTION}

In the environment around Japan's Fukushima Daiichi Nuclear Power Plant, the enormous area of damage requires extensive surveying to investigate the ambient dose rate and radioactive surface contamination. ${ }^{1-4)}$ Thus, the number of survey meters must be dramatically increased, ${ }^{5,6)}$ and detector costs must be kept low.

Aromatic ring polymers are attractive scintillation materials for radiation detectors because they are inexpensive and can be easily produced. ${ }^{7-15}$ ) We have previously developed a scintillation substrate from common polyethylene naphthalate (PEN), and evaluated its overall performances for radiation detection.

An important characteristic of a scintillation substrate is the refractive index for light generated in the material. ${ }^{16)}$ For PEN, light with a $425-\mathrm{nm}$ emission peak is emitted and the effective refractive index is 1.70 over its emission spectrum. ${ }^{17-20)}$ Additionally, it has other attractive properties such as transparency, heat tolerance, gas and moisture impermeability, chemical inertness, and a density of $1.33 \mathrm{~g} / \mathrm{cm}^{3}$. Energy spectra of some radiations were recently demonstrated for PEN. ${ }^{21-27)}$

For a survey meter with a large detection window, we created a thin sheet of scintillation material from PEN and demonstrated its radiation counting response at different

*1 Kyoto University Research Reactor Institute; 2, Asashiro-Nishi, Kumatori-cho, Sennan-gun, Osaka 590-0494, Japan.

E-mail: philip@rri.kyoto-u.ac.jp

*2 National Institute of Radiological Sciences; 4-9-1, Anagawa, Inageku, Chiba-shi, Chiba 263-8555, Japan. locations on the detection window. This knowledge will be useful for designing a full-scale radiation detector.

\section{MATERIALS AND METHODS}

A $72 \times 140 \times 0.5 \mathrm{~mm}$ thin PEN sheet (Teijin, Ltd.) with one face enhanced with prism treatment to propagate more light emitted from the PEN sheet to reach the photodetector was created. The structure possesses a naphthalate ring:

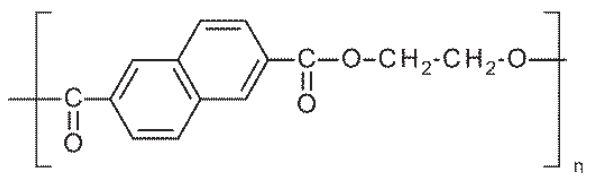

To get optimum results, the sheet was mounted to the detection part of a common survey meter (SPS-210Z, Ohyo Koken Kogyo Co., Ltd.). Figure 1 shows the schematic of the detection part and the defined coordinates. The treated PEN face was oriented away from the photomultiplier tube (PMT). There is no bulking agent in the detection part of the survey meter.

The experimental setup for measuring radiation counts is shown in Fig. 2. The PEN sheet was irradiated by beta particles emitted from a ${ }^{90} \mathrm{Sr}$ radioactive source (149 Bq, 9 October 2008; Nuclitec $\mathrm{GmbH}$ ) via an acryl collimator. The center of the source was placed over a $9 \times 23$ array of different locations on the detection window. The time constant of the survey meter was set to $30 \mathrm{~s}$, and the count rates were read after $90 \mathrm{~s}$ from the start of irradiation. At each location on the detection window, the data taking was performed 10 times and the results were averaged. 
a)

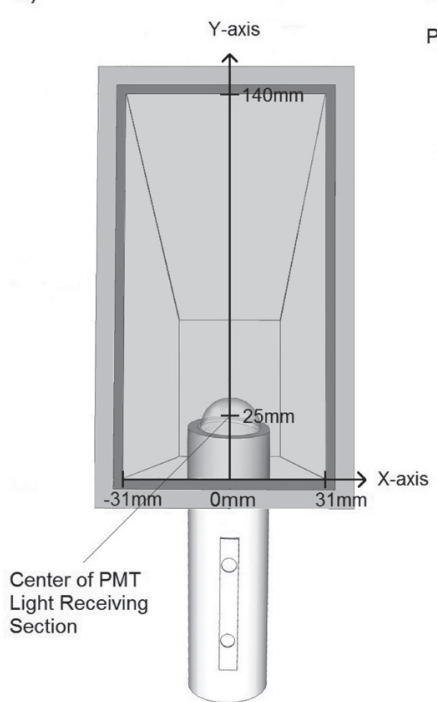

b)

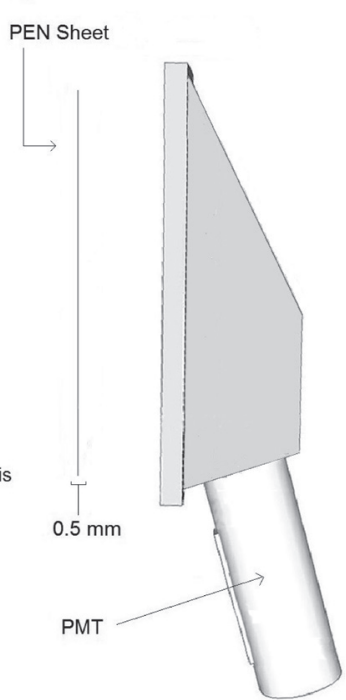

Fig. 1 Schematic of the detection part and defined coordinates (a) Bottom view after removing the PEN sheet. (b) Side view. There is no bulking agent.

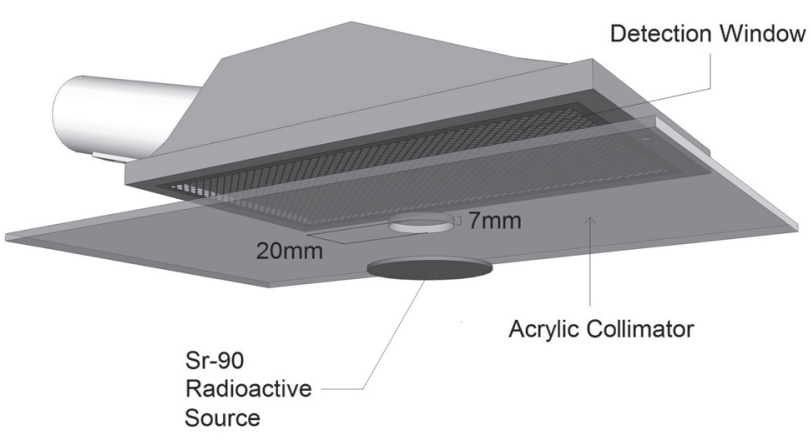

Fig. 2 Schematic of the setup for measuring radiation counts. Beta particles emitted from a ${ }^{90} \mathrm{Sr}$ radioactive source via an acryl collimator irradiate a $9 \times 23$ array of points on the detection window.

\section{RESULTS AND DISCUSSION}

Figure 3 shows the count rate distribution on the detection window. This position dependence was primarily caused by the relatively high refractive index of PEN and the geometry between the PEN sheet and the PMT. The refractive index determines the critical angles of total reflection. Thus, more light emitted from the PEN sheet is directly detected at the high count rate region in Fig. 3, the location near the center of the PMT light receiving section $(X=0 \mathrm{~mm}, \mathrm{Y}=25 \mathrm{~mm})$ in Fig. 1. The low count rate regions occur because the propagation length for the emitted light is longer.

Figure 4 plots the count rates along the Y-axis monitored at $\mathrm{X}=0 \mathrm{~mm}$, while Fig. 5 plots the count rates along the $\mathrm{X}$-axis at $Y=25 \mathrm{~mm}$. The variability for the count rates along each axis was obtained by dividing the maximum value by the

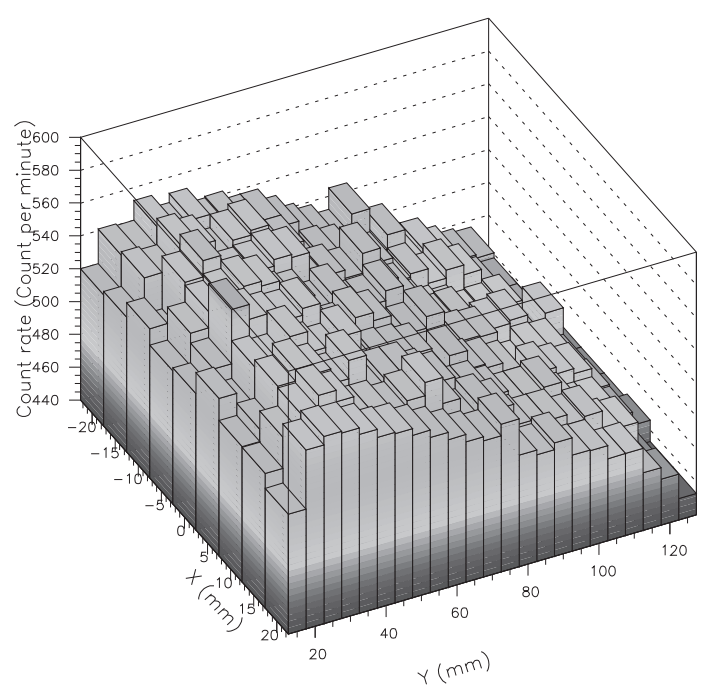

Fig. 3 Count rate distribution along the detection window. The center of the PMT light receiving section is placed at the coordinates $X=0 \mathrm{~mm}$ and $\mathrm{Y}=25 \mathrm{~mm}$.

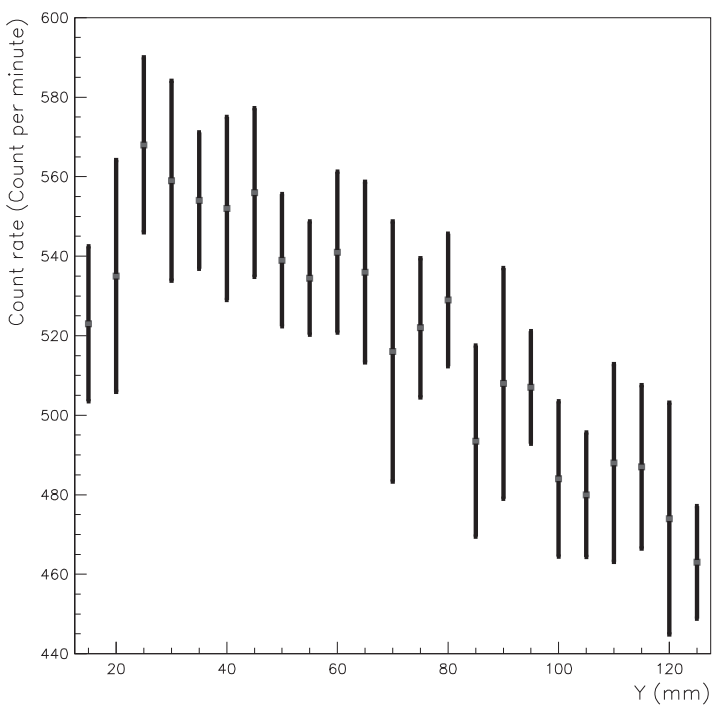

Fig. 4 Count rates along the $\mathrm{Y}$-axis monitored at $\mathrm{X}=0 \mathrm{~mm}$.

minimum value, respectively. Along the Y-axis, the variability was 1.23 . In contrast, the variability was 1.05 along the $\mathrm{X}$-axis.

These results should be useful for designing a radiation detector based on PEN. Thus, a position-sensitive detector should take into account the count-rate position dependence. It is advantageous to keep the PEN sheet perpendicular to the light receiving section of the photodetector in order to directly detect the emitted light.

\section{CONCLUSION}

We have mounted a thin sheet from the aromatic polymer PEN in a survey meter. The radiation counting response was obtained from a $9 \times 23$ array of different locations on the detection window of the PEN survey meter. The radiation 


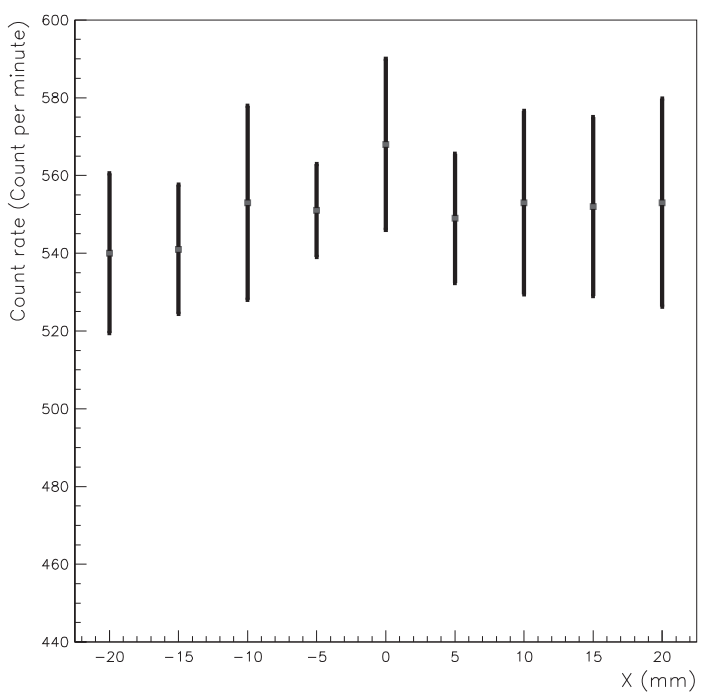

Fig. 5 Count rates along the $\mathrm{X}$-axis monitored at $\mathrm{Y}=25 \mathrm{~mm}$.

count variability on the detection window of the survey meter was 1.23 along the $\mathrm{X}$-axis and 1.05 along the Y-axis. These results could be useful for the design of radiation detectors mounting PEN sheets.

\section{ACKNOWLEDGEMENTS}

The authors thank the KUR Research Program for the Scientific Basis of Nuclear Safety for partial support at this work. The authors would like to thank Mr. T. KamatA, Mr. T. Miyagawa (Ohyo Koken Kogyo Co. Ltd.), Mr. F. Murakawa and Z. ShIDARA (Teijin Ltd.) for their assistance. The authors are grateful to Dr. H. Yamana, Dr. T. TAKahashi, Dr. N. Sato, Ms. K. Fujiwara, Mr. M. Kanayama, Mr. T. Miyake (Kyoto University), Mr. H. KitAmURA and Ms. M. YASAKU (National Institute of Radiological Sciences) for their cooperation.

\section{REFERENCES}

1) Y. Shirakawa, H. Nakamura, T. Kamata, K. Watai, M. Mitsunaga, Z. Shidara and F. Murakawa; Radiation counting characteristics on surface-modified polyethylene naphthalate scintillators, Radioisotopes, 62, 879 (2013).

2) H. Iida, T. Kamata, K. Watai, H. Amano and Y. ShIRAKAWA; Quick Response of a Survey Meter by a Dynamic Prediction Method. Radioisotopes, 56 (7), 351 (2007).

3) H. Iida, T. Kamata, K. Watai, H. Amano and Y. ShIRAKAWA; Application of a Dynamic Prediction Survey Meter to Co-60 Contamination Monitoring, Radioisotopes, 57 (11), 669 (2008).

4) Y. ShIRAKAWA; Quick response of a survey meter in static condition. Radioisotopes, 54, 199 (2005).

5) Y. Shirakawa, H. Nakamura, T. Kamata and K. Watai; A fast response radiation detector based on a response prediction method for decontamination, Radiat. Meas., 49, 115 (2013).

6) H. Nakamura, Y. Shirakawa, N. Sato, H. Kitamura and S. TAKAHASHI; Undoped polycarbonate for detection of environmental radiation, Jpn. J. Health Phys., 49 (2), 98 (2014).

7) H. Nakamura, Y. Shirakawa, H. Kitamura, N. Sato, O. Shinj, K. SAIto and S. TAKahashi; Optical characteristics of pure poly (vinyltoluene) for scintillation applications. Nucl. Instrum. Methods Phys. Res. A, 770, 131 (2015).

8) H. Nakamura, Y. Shirakama, H. Kitamura, N. Sato, O. Shinji, K. Saito and S. TAKahashi; Mechanism of wavelength conversion in polystyrene doped with benzoxanthene: emergence of a complex, Sci. Rep., 3, 2502 (2013).

9) V. Kumar, Y. Ali, R. G. Sonkawade and A. S. Dhaliwal; Effect of gamma irradiation on the properties of plastic bottle sheet, Nucl. Instrum. Method Phys. Res. B, 287, 10 (2012).

10) H. Nakamura, Y. Shirakawa, S. Takahashi, T. Yamano, Y. Kobayashi, R. Hazama, C. Takagi and O. Hasebe; Cheap educational materials for understanding radiation, Phys. Educ., 47, 17 (2012).

11) H. Nakamura, H. Kitamura and R. Hazama; Radiation measurements with heat-proof polyethylene terephthalate bottles, Proc. R. Soc. A., 466, 2847 (2010).

12) S. Nagata, H. Katsui, K. Hoshi, B. Tsuchiya, K. Toh, M. Zhao, T. Shikama and E. R. Hodgson; Recent research activities on functional ceramics for insulator, breeder and optical sensing systems in fusion reactors, J. Nucl. Mater, 442, S501 (2013).

13) H. Nakamura, Y. Shirakawa, H. Kitamura, N. Sato and S. TAKAHASHI; Poly (ether sulphone) as a scintillation material for radiation detection, App. Radiat. Isot., 86, 36 (2014).

14) H. Nakamura, Y. Shirakawa, N. Sato, T. Yamada, H. Kitamura and S. Takahashi; Optimised mounting conditions for poly (ether sulfone) in radiation detection, App. Radiat. Isot., 91, 131 (2014).

15) H. NaKamura, Y. Shirakawa, N. Sato, H. Kitamura and S. TAKAHASHI; Undoped poly (phenyl sulfone) for radiation detection, Radiat. Meas., 73, 14 (2015).

16) H. Nakamura, Y. Shirakawa, H. Kitamura, N. Sato, O. Shinj, K. SAito and S. TAKahashi; Light propagation characteristics of high-purity polystyrene, App. Phys. Lett., 103, 161111 (2013).

17) W. Sellmeier; Zur Erklärung der abnormen Farbenfolge im Spectrum einiger Substanzen, Annalen der Physik, 219, 272 (1871).

18) H. Nakamura, Y. Shirakawa, H. Kitamura, N. Sato and S. TAKAHASHI; Detection of alpha particles with undoped poly (ethylene naphthalate), Nucl. Instrum. Method Phys. Res. A, 739, 6 (2014).

19) H. Nakamura, Y. Shirakawa, H. Kitamura, T. Yamada, Z. Shidara, T. Yokozuka, P. Nguyen, T. Takahashi and S. TAKAhashi; Radiat. Meas, Blended polyethylene terephthalate and polyethylene naphthalate polymers for scintillation base substrates, Radiat. Meas., 59, 172 (2013).

20) H. Nakamura, Y. Shirakawa, N. Sato, H. Kitamura and S. TAKAHASHI; Blended poly (ether sulfone) and poly (ethylene naphthalate) as a scintillation material, Nucl. 
Instrum. Methods Phys. Res. A, 759, 1 (2014).

21) G. H. V. Bertrand, M. Hamel and F. Sguerra; Current status on plastic scintillators modifications, Chemistry- $A$ Eur. J., 20 (48), 15660 (2014).

22) H. NaKamura, Y. Shirakawa, S. Takahashi and $H$. Shimizu; Evidence of deep-blue photon emission at high efficiency by common plastic, EPL (Europhysics Letters), 95 (2), 22001 (2011).

23) R. Uppal, I. Sen, D. Penumadu, S. Young, M. J. Urffer and L. F. Miller; 6Li Embedded Biaxially Stretched Scintillation Films for Thermal Neutron Detection and Neutron/Gamma Discrimination, Adv. Eng. Mater., 16, 196 (2013).

24) H. Nakamura, T. Yamada, Y. Shirakawa, H. Kitamura, Z. Shidara, T. Yokozuka, P. Nguyen, M. Kanayama and
S. TAKAhashi; Optimized mounting of a polyethylene naphthalate scintillation material in a radiation detector, Appl. Radiat. Isot., 80, 84 (2013).

25) S. Nagata, M. Mitsuzuka, S. Onodera, T. Yaegashi, K. Hoshi, M. Zhao and T. Shikama; Damage and recovery processes for the luminescence of irradiated PEN films, Nucl. Instrum. Method Phys. Res. B, 315, 157 (2013).

26) H. NaKamura, Y. Shirakawa, N. Sato and S. Takahashi; Characterising radiation spectra with stacked plastic sheets, Phys. Educ., 49 (2), 135 (2014).

27) I. Sen, M. Urffer, D. Penumadu, S. A. Young, L. F. Miller and A. N. Mabe; Polyester composite thermal neutron scintillation films, IEEE Trans. Nucl. Sci., 59 (4), 1781 (2012). 